\title{
A FORMAÇÃO DE EDUCADORAS/ES AMBIENTAIS A PARTIR DO PIBID: REFLEXÕES SOBRE LIMITES E POSSIBILIDADES
}

\author{
Gabriela Santos Tibúrcio ${ }^{1}$ \\ Amadeu José Montagnini Logarezzi²
}

\section{Resumo}

Este artigo tem como objetivo colaborar com a produção de conhecimento sobre formação docente em educação ambiental em uma perspectiva crítica, a partir das experiências de um grupo do Pibid da Unesp de Rio Claro. A pesquisa contou com a participação de estudantes do curso de ciências biológicas e de uma professora de ciências e de biologia da rede pública de ensino, sendo desenvolvida a partir das orientações da metodologia comunicativo-crítica. Foram realizados grupos de discussão comunicativos e as análises da pesquisa buscaram identificar elementos transformadores e obstaculizadores em relação ao tema investigado. Os resultados evidenciaram possibilidades reais e viáveis de práticas de educação ambiental em uma perspectiva crítica, no contexto escolar, a partir do Pibid e, com isso, consideramos de grande importância programas de formação docente que ofereçam às/aos licenciandas/os um contato mais estreito com a escola, a partir de um trabalho coletivo e interdisciplinar.

Palavras-chave: Educação ambiental. Metodologia comunicativo-crítica. Pibid. Formação docente.

\section{ENVIRONMENTAL TEACHERS' TRAINING FROM PIBID: REFLECTIONS ABOUT LIMITS AND POSSIBILITIES}

\begin{abstract}
This article has as goal to contribute to the construction of knowledge about environmental education teachers' training, in a critical perspective, from the experience of a group of Pibid from Unesp of Rio Claro. The research included the participation of students of biological sciences course and of a science teacher of public school and it has been developed from the communicative-critical methodology orientations. Communicative discussion groups were conducted and the analysis of the research sought to identify transformative elements and barriers elements for the theme of research. The results showed real and viable possibilities of environmental education practices, in a critical perspective, in the context of schools from Pibid and, therewith, we consider of great importance programs of teacher training that offer to undergraduate students a closer contact with the school context, from a collective and interdisciplinary work.
\end{abstract}

Keywords: Environmental education. Critical communicative methodology. Pibid. Teachers' training.

\section{LA FORMACIÓN DE LAS/OS EDUCADORAS/ES AMBIENTALES DESDE PIBID: REFLEXIONES SOBRE LÍMITES Y POSIBILIDADES}

\footnotetext{
${ }^{1}$ Mestre em Ciências Ambientais pela Ufscar e aluna do programa de pós-graduação em Educação Ambiental pela Universidade de São Paulo (USP/ESALQ)

${ }^{2}$ Professor titular aposentado da Ufscar, coordenador do Grupo de Estudo e Pesquisa em Educação Ambiental (Gepea / Ufscar) e membro do Núcleo de Investigação e Ação Social e Educativa (Niase / Ufscar)
} 


\section{Resumen}

Este artículo tiene como objetivo colaborar con la producción de conocimiento en formación docente en educación ambiental en una perspectiva crítica, a partir de las experiencias de un grupo de Pibid de la Unesp de Río Claro. El estudio contó con la participación de estudiantes de ciencias biológicas y de una maestra de ciencia y biología de la escuela pública y se desarrolló a partir de directrices de la metodología comunicativa crítica. Se realizaron grupos de discusión comunicativos y los análisis de la investigación buscaron identificar elementos transformadores y obstaculizadores en relación al tema investigado. Los resultados mostraran condiciones reales y viables para las prácticas de educación ambiental en una perspectiva crítica en el contexto escolar desde Pibid y, con eso, consideramos de gran importancia programas de formación de maestras/os que proporcionan a las/los estudiantes un contacto más estrecho con la escuela, a partir de un trabajo colectivo e interdisciplinario.

Palabras-clave: Educación ambiental. Metodología comunicativa crítica. Pibid. Formación del profesorado.

\section{Introdução}

As discussões sobre a questão ambiental, temática presente desde os aspectos cotidianos das pessoas até os âmbitos governamentais internacionais, têm sido consideradas como de grande relevância para diferentes segmentos da sociedade. Veiculadas pela grande mídia, questões como o aquecimento global, escassez de recursos hídricos, poluição, entre outras têm sido cada vez mais preocupantes no que tange à sobrevivência humana e às consequências que esses problemas podem acarretar em nossas vidas (CAVALARI, 2009).

Podemos observar, nesse sentido, certa concordância em relação à seriedade da condição planetária atual, concernente a diferentes grupos sociais, chamada por Carvalho, L. (2006, p. 20) de "consenso aparente", assim como certo consenso em relação à necessidade urgente de ações que caminhem na direção de minimizar esses impactos ambientais ou, em uma visão mais otimista, de reverter essa situação.

Entretanto, muitas/os autoras/es ${ }^{3}$ consideram que essa problemática vai além de uma crise ambiental, podendo ser entendida como uma crise civilizatória, de valores, fruto da ciência moderna, caracterizada pela racionalidade tecnocientífica, mecanicista, pela visão racionalista de mundo, marcada pela dualidade sociedade e natureza (GRUN, 2001; LEFF, 2002; CAVALARI, 2007).

Para Leff (2002, p. 191),

[...] a crise ambiental é a crise do nosso tempo. O risco ecológico questiona o conhecimento do mundo. Essa crise apresenta-se a nós como um limite do real, que ressignifica e reorienta o curso da história: limite do crescimento econômico e populacional; limite dos desequilíbrios ecológicos e das capacidades de sustentação da vida; limite da pobreza e da desigualdade social. Mas também crise do pensamento ocidental: da "determinação metafísica" que, ao pensar o ser como ente, abriu caminho para a racionalidade científica e instrumental que produziu a modernidade como uma ordem coisificada e fragmentada, como formas de domínio e controle sobre o mundo. Por isso, a crise ambiental é acima de tudo um problema de conhecimento.

\footnotetext{
${ }^{3}$ Ao longo do texto, optamos pela inclusão dos dois gêneros do substantivo, tendo em vista a ruptura (ora em curso) com a ideologia machista hegemônica, enraizada em nossa linguagem, tanto escrita quanto falada. De acordo com Paulo Freire (2011, p. 94) "a recusa à ideologia machista, que implica necessariamente a recriação da linguagem, faz parte do sonho possível em favor da mudança do mundo".
} 
Assim, concordamos que o modelo de racionalidade vigente é fator determinante do padrão atual de relacionamento entre sociedade e natureza e, como consequência, da crise ambiental. Nesse sentido, faz-se necessária a construção de uma nova visão do mundo, da nossa relação - enquanto seres sociais e conscientes - com a natureza; fazem-se necessárias reflexões éticas sobre nossa atuação no planeta, para a construção de novas formas de relação que se pautem em valores condizentes com essas mudanças (BONOTTO, 2012, p. 46).

A partir dessa necessidade de se olhar a realidade considerando sua complexidade, de forma interdisciplinar, é imprescindível que se busque uma reorientação da atuação humana em sua relação com o meio ambiente. Em tal contexto, a educação ambiental surge não só como uma necessidade, mas também como esperança. De acordo com Logarezzi (2006, p. 93),

[...] a concepção de educação apresentada como educação ambiental postula a construção de um mundo, com sua contribuição, referenciado pela presença de 'sociedades sustentáveis', cujo plural é significativo e representa o respeito à multiculturalidade, com destaque à regionalidade e à temporalidade de cada contexto sociocultural, em cujo desenvolvimento é central a participação democrática das(os) cidadã/os e imperativa a condição de sustentabilidade socioambiental regional e planetária e em curto e longo prazos.

Dentro do campo da educação ambiental coexistem múltiplas práticas educativas, correntes de pensamento e fundamentos teóricos ${ }^{4}$. Muitas dessas práticas, em especial no contexto escolar, se dão a partir de uma abordagem descritiva e classificatória dos elementos, fenômenos e processos naturais, em que os componentes da natureza são apresentados de forma isolada, desconsiderando a complexidade das interações entre eles e os processos dinâmicos de transformação da natureza (CARVALHO, L., 2006, p. 29-30). De modo mais amplo, essa visão a-histórica e reducionista da natureza, que pode prejudicar o entendimento da realidade e a intervenção nela de uma forma mais crítica, encontra-se, geralmente, presente na chamada educação ambiental conservadora.

Por outro lado, temos a vertente que pode ser chamada de educação ambiental crítica, que objetiva promover ambientes educativos em que haja mobilização de processos de intervenção sobre a realidade e seus problemas socioambientais, assumindo, de forma inalienável, sua dimensão política no processo de formação da/o educanda/o (GUIMARÃES, 2004). Loureiro et al. (2009, p. 89) complementam, dizendo que essa educação ambiental "compromete-se com a formação de sujeitos ambientalmente responsáveis, cujo compromisso social, histórico e político é a construção de sociedade sustentáveis".

Dessa forma, para uma educação ambiental crítica, a emancipação do sujeito é início e fim de todo processo educativo que visa transformar nosso modo de vida, o qual inclui "a superação das relações de expropriação, dominação e preconceitos; a liberdade para conhecer e gerar cultura tornando-nos autônomos em nossas escolhas" (LOUREIRO, 2007, p. 70).

Pensando, então, em uma formação que contemple os aspectos apontados para uma educação ambiental crítica, nas propostas de Carvalho, L. (1999) encontram-se três dimensões a serem desenvolvidas nas práticas pedagógicas: uma primeira, relacionada à natureza dos conhecimentos acumulados historicamente; uma segunda, relacionada aos valores éticos e estéticos; uma terceira, relacionada à participação política do sujeito na sociedade.

\footnotetext{
${ }^{4}$ Lucy Sauvé (2005) cita uma pluralidade de correntes de pensamento e de práticas existentes na educação ambiental, entre elas: a naturalista, a conservacionista, a solucionadora de problemas, a sistêmica, a holística, a humanista, a crítica, a biorregional, a feminista etc., que correspondem a outros tantos modos complementares de ligar-se ao meio ambiente.
} 
A primeira dimensão possibilita aos sujeitos do processo educativo, além do acesso aos conhecimentos produzidos socialmente e acumulados historicamente, pensar o processo de produção do conhecimento científico, que está influenciado pelos processos históricos, culturais e políticos, portanto, "significa, também, considerar a ciência como uma atividade tipicamente humana e por isso sujeita a enganos, erros ou distorções de diversas naturezas" (CARVALHO, L., 1999, p. 36).

Na segunda dimensão - valores éticos e estéticos - Bonotto (2008) considera que, cotidianamente, estamos fazendo juízos de valores e que, portanto, julgamos as situações, as coisas, as pessoas, como sendo boas ou ruins, segundo os valores que lhes atribuímos. Assim, "os seres humanos, em sociedade e através de escolhas sucessivas, constroem formas de viver que se diferenciam em tempo e lugares diversos, criando os diferentes valores e originando os diferentes costumes" (BONOTTO, 2012, p. 37). Tais valores podem ser dialogados e transformados, na medida em que as pessoas decidam o que é melhor para o grupo, tanto individualmente quanto coletivamente. Nesse sentido, decorre que contextos multiculturais (em que o mundo é um exemplo extremo) são desafiados a promover a interculturalidade.

Já a terceira dimensão está relacionada ao desenvolvimento da participação política, visando à construção da cidadania e de uma sociedade democrática. Nesse sentido, é indispensável que os procedimentos utilizados pelas/os educadoras/es, em sua prática docente, possibilitem o desenvolvimento de um espírito cooperativo e solidário, em busca de relações mais humanizadoras e igualitárias (CARVALHO, L., 1999), ampliando os valores para além dos que já estão presentes.

Assim, diferentemente de uma postura conservadora em educação ambiental, que se pauta em ações individualizadas, essa dimensão possibilita aos sujeitos do processo educativo que se transformem, ao se organizarem coletivamente para provocar transformações sociais que caminhem na direção de uma sociedade democrática. Nesse sentido, Freire (2005) traz como reflexão o papel da escola pública enquanto espaço de organização política, de reflexões, de experiências, e da/o professora/or enquanto aquela/e que busca práticas educativas progressistas, que respeitem o saber de experiência feito das/os educandas/os, que as/os inquietem, fazendo com que percebam que o mundo pode ser mudado, transformado, reinventado. O papel da/o professora/or

[...] conscientemente progressista é testemunhar a [suas/]seus alun[as/]os, constantemente, sua competência, amorosidade, sua clareza política, a coerência entre o que diz e o que faz, sua tolerância, isto é, sua capacidade de conviver com [as/]os diferentes para lutar com [as/]os antagônicos. É estimular a dúvida, a crítica, a curiosidade, a pergunta, o gosto do risco, a aventura de criar (FREIRE, 2005, p. 54).

Assim, reforça-se a impossibilidade da neutralidade da escola e das/os professoras/es que, enquanto seres políticos, ao fazerem a escolha por "prática educativa progressista, competente, também procurem, ao ensinar os conteúdos, desocultar a razão de ser daqueles problemas" (FREIRE, 2005, p. 30). Para Freire (2005, p. 119-120) a diretividade faz parte da natureza mesma do ser da educação.

A educação marcha constantemente além dela mesma. Não há educação sem objetivos, sem finalidades. É isso que, fazendo-a diretiva, não permite sua neutralidade ou a neutralidade $\mathrm{d}[\mathrm{a} / \mathrm{J}$ o educador[a/or]. Partindo-se do fato de que toda prática educativa é diretiva, por sua própria natureza, a questão que se coloca para educador[as/]es progressistas coerentes, quer dizer, que fazem o possível para diminuir a distância entre o que dizem e o que fazem, é não permitir que a diretividade se perverta em autoritarismo ou manipulação ou, também, que a diretividade, fragilizada, se perca na falta de limite da licenciosidade. 
E, para Freire (2011), educadoras/es progressistas devem construir uma postura dialógica e dialética, trabalhando o processo do ato de aprender, fundamentado na consciência da realidade vivida pelas/os educandas/os e jamais reduzir-se ao simples conhecer das palavras. Para Fiori (2013, p. 11), a educação libertadora como prática da liberdade "só encontrará adequada expressão numa pedagogia em que [a/]o oprimid[a/]o tenha condições de, reflexivamente, descobrir-se e conquistar-se como sujeito de sua própria destinação histórica". Nesse sentido, o autor entende que alfabetizar-se é "aprender a escrever a sua vida, como autor[a/or] e testemunha de sua história, isto é, biografar-se, existenciar-se, historicizarse" (FIORI, 2013, p. 12). Nesse sentido, a formação de educadoras/es ambientais para trabalhar no contexto escolar ganha grande importância.

\begin{abstract}
É a natureza social da escola, sua tarefa educativa por excelência, dando significado ao mundo via conhecimento sistematizado, a intensidade dos relacionamentos humanos que ali ocorrem, que a tornam o ambiente adequado e facilitador para despertar a consciência individual e coletiva, tão necessária às mudanças de atitudes e de valores necessários para mudar o curso da história (CARVALHO, M., 2012, p. 25).
\end{abstract}

Apesar disso, Sato (2001) pontua como a educação ambiental está ausente, de forma geral, nos currículos tanto de cursos de graduação, como de pós-graduação, bem como em cursos de formação continuada.

$\mathrm{Na}$ busca por superar os desafios citados, a Coordenadoria de Aperfeiçoamento de Pessoal de Nível Superior (Capes) criou, em 2007, o Programa Institucional de Bolsas de Iniciação à Docência (Pibid), de nível nacional, que tem como objetivo proporcionar a estudantes da licenciatura - junto à educadoras/es em formação continuada da rede pública de ensino (professoras/es supervisoras/es) e orientadas/os por professoras/es coordenadoras/es da universidade - uma formação docente mais qualificada que contribua com o processo de consolidação da profisssão docente.

Considerando a importância das formações inicial e continuada de professoras/es da rede pública de ensino abrangerem, fundamentadamente, a temática ambiental, um grupo da Universidade Estadual Paulista Júlio de Mesquita Filho (Unesp) do campus de Rio Claro, que aderiu ao Pibid em 2009, a partir do subprojeto Parceria Unesp e escolas de ensino básico: articulando a formação inicial e continuada nas ciências da natureza, biologia, física e educação física, buscou desenvolver práticas de educação ambiental no contexto escolar da rede pública de ensino fundamental e médio, visando o fortalecimento da parceria entre escolas de educação básica do município de Rio Claro e a universidade, a partir da troca de saberes $^{5}$ entre as/os envolvidas/os e da formação compartilhada das/os estudantes de graduação dos cursos de ciências biológicas e de educação física ${ }^{6}$ nesses dois contextos.

A partir dos elementos apontados anteriormente, esta pesquisa visou contribuir com a construção do conhecimento sobre práticas docentes em educação ambiental, em uma perspectiva crítica, através da análise de procedimentos didáticos, materiais e reflexões do grupo de educadoras/es que participaram do Pibid no subprojeto acima referido, em uma

\footnotetext{
5 Optamos pela expressão troca de saberes ao longo do texto, ao invés de troca de conhecimentos, pois entendemos que não se trata, apenas, de troca de conhecimentos de nível científico, mas também de saberes advindos das experiências, das práticas, das percepções e da subjetividade de cada sujeito envolvido, referida nas intersubjetividades dos grupos/âmbitos sociais (mundos da vida) de que participa.

${ }^{6}$ Por questões estruturais (em especial a falta de horário em comum), o diálogo para se pensar essa proposta ficou restrito ao grupo de bolsistas da biologia e da educação física. O grupo da física não participou do projeto interdisciplinar e continuou desenvolvendo as atividades referentes ao Pibid de maneira isolada, como fizeram nos anos iniciais os demais grupos (biologia e educação física).
} 
proposta de trabalho interdisciplinar, buscando aproximar as práticas utilizadas e a realidade da escola pública e de suas/seus educadoras/ores.

\section{Metodologia e procedimentos de análise}

A construção desta pesquisa foi realizada a partir das orientações da metodologia comunicativo-crítica (GÓMEZ et al., 2006), em que todas as pessoas participantes da pesquisa atuam conjuntamente no processo investigativo, desde o delineamento da pesquisa até a análise dos dados. As pesquisas realizadas com base nessa metodologia implicam diálogo permanente e igualitário entre as/os pesquisadoras/es e as demais pessoas envolvidas nas comunidades e realidades em estudo. Para esse diálogo, as/os pesquisadoras/es trazem o conhecimento científico existente e os sujeitos do contexto pesquisado contribuem com os conhecimentos de suas vivências e experiências. Nesse processo dialógico, dos novos entendimentos emergem articulações com vistas a coordenar planos de ação transformadora em busca de possíveis soluções aos problemas sociais. Com base nesses novos conhecimentos, as/os agentes poderão sugerir novas políticas sociais, que sejam eficazes. Nesse sentido, o trabalho buscou a construção de um conhecimento dialógico, na abordagem coletiva dos dados, de modo a se encontrarem, dialógica e dialeticamente, os conhecimentos ricamente práticos e contextuais dos sujeitos da pesquisa com os conhecimentos essencialmente teóricos e acadêmicos desta pesquisadora.

Utilizamos como técnica de coleta, no presente artigo, o grupo de discussão comunicativo - tal como descrito por Gómez et al. (2006, p. 81-83) -, em que diferentes olhares sobre os temas da pesquisa foram colocados em contato para propiciar uma confrontação dialógica entre as subjetividades individual e coletiva, na perspectiva da metodologia comunicativo-crítica. $\mathrm{O}$ grupo de discussão comunicativo foi composto por seis pessoas que participaram do subprojeto acima referido, nos anos de 2012 e/ou 2013, sendo elas quatro ex-bolsistas do Pibid da licenciatura em biologia (uma licenciada e professora da rede pública de ensino e três licenciandas/os), uma professora supervisora (professora de ciências da rede pública de ensino) e a pesquisadora, em encontros de aproximadamente uma hora e meia, no Departamento de Educação na Unesp (campus de Rio Claro). As discussões focalizaram o tema da educação ambiental e o processo de formação nesse campo.

As discussões realizadas nos referidos grupos foram registradas através do uso de gravador digital e, posteriormente, foram transcritas e sistematizadas pela pesquisadora para, em sequência, serem interpretadas e categorizadas pelas/os demais participantes da pesquisa, de forma coletiva. Foi consensuado entre todas/os o uso público de nomes fictícios, de modo a garantir em confidência a identidade das/os participantes da pesquisa. A partir das orientações da metodologia utilizada, buscamos a interpretação coletiva dos dados a partir da interação dialógica entre a pesquisadora e as pessoas participantes da pesquisa, visando à validação das análises realizadas previamente pela pesquisadora. Uma análise que, pela via da práxis, teve como direção a construção de um conhecimento que fosse em si já transformador, mobilizador de transformação, e que, com isso, potencializasse a capacidade transformadora das pessoas envolvidas em relação aos desafios e às possibilidades da educação ambiental, em seus aspectos gerais e, em particular, no do contex to escolar e do Pibid.

Nesse sentido, buscamos categorizar os dados obtidos na discussão como elementos obstaculizadores ou transformadores para a educação ambiental no contexto escolar, além de vinculá-los aos âmbitos do mundo da vida e do sistema, a partir do conceito de sociedade dual de Habermas (2012a), tendo como base falas das/os participantes relacionadas ao tema da pesquisa, sempre de acordo com a metodologia comunicativo-crítica. Para o referido autor, a sociedade é composta, simultaneamente, pelo mundo da vida e pelo sistema, sendo que no 
primeiro âmbito ocorrem as interações interpessoais, as relações comunicativas, enquanto o segundo é marcado por aspectos estruturais, como a economia, as leis etc. e que "o mundo da vida e o sistema se diferenciam não somente à proporção que a racionalidade de um e a complexidade do outro crescem [internamente], mas também à medida que um se diferencia do outro" (HABERMAS, 2012b, p. 277). Trata-se, aqui, de um processo de tripla diferenciação progressiva: diferenciação interna do mundo da vida, se tornando cada vez mais racional, diferenciação interna do sistema, se tornando cada vez mais complexo, e diferenciação de desacoplamento um do outro, lembrando que ambos são originários da sociedade como um todo e a ela continuam pertencentes, componentes imbricados que a constituem dialeticamente. Para Habermas (2012b, p. 280-281), em relação à diferenciação desses dois âmbitos,

[...] quando tal tendência à separação entre sistema e mundo da vida é transladada para o nível de uma história sistemática das formas de entendimento, torna-se possível descobrir a ironia que se oculta no processo de esclarecimento da história mundial, a saber: a racionalização do mundo da vida intensifica a complexidade do sistema, atingindo um ponto em que os imperativos do sistema, libertos, detonam a capacidade hermenêutica do mundo da vida, instrumentalizando-o.

$\mathrm{Na}$ metodologia comunicativo-crítica esse imbricamento entre eles e esse processo de colonização do mundo da vida pelo sistema, sobretudo como decorrência da importância da linguagem e dos valores prático-morais (normas...), importância que vai se reduzindo na complexificação do sistema que, no desenvolvimento da busca do êxito como sua motivação de atuação, se libera desses aspectos que são tão caros ao entendimento racional no âmbito do mundo da vida (linguagem, normas...). Tal situação, de tripla diferenciação, comporta, em princípio, tanto atuação do mundo da vida sobre o sistema, como do sistema sobre o mundo da vida. O problema é que, historicamente e em especial na modernidade, segundo Habermas, essa segunda via de influência tem preponderado sobre a primeira, com prejuízo para as formas de atuação linguísticas/interpretativas/intersubjetivas, que visam o entendimento, as quais são invadidas e colonizadas pelas formas de atuação estruturadas/hierarquizadas, que visam o êxito. A ironia histórica a que ele se refere é que a própria racionalização (do mundo da vida) é que, por gerar e intensificar a complexificação (do sistema) no desenvolvimento da vida em sociedade, acaba por ser colonizada pelos imperativos do sistema, num processo em que a instrumentalização, típica do sistema, da orientação ao êxito, acaba por se sobrepor à solidariedade, que, no mundo da vida, deveria ser princípio básico da orientação ao entendimento que lhe é própria. Nesse contexto, de acordo com Habermas (e em consonância com Freire, 2013, e Flecha, 2014) é possível agir no sentido de atenuar ou superar essa patologia da referida colonização, dado o imbricamento entre os âmbitos em questão, em que se pode destacar o fato de que são os sujeitos, os mesmos que compõem os mundos da vida, que definem e constituem as instituições do sistema.

Levando em consideração que cada pessoa participante da pesquisa está inserida em um mundo da vida particular (composto pelos planos do mundo objetivo, do social e do subjetivo) e cada contexto desses proporciona a elas diferentes saberes de fundo, a partir da intersubjetividade que caracteriza o contexto, essa pesquisa buscou garantir todos esses saberes em suas análises (HABERMAS, 2012a, p. 570).

Dessa forma, a partir das discussões sobre as diferentes atividades de educação ambiental realizadas no subprojeto em questão, entre os anos de 2012 e 2013, no contexto escolar e de formação docente, o trabalho buscou identificar desafios e possibilidades encontrados nessas práticas, a fim de evidenciar condições reais e viáveis para a elaboração e execução de práticas de educação ambiental por professores da rede pública nas escolas. 


\section{Resultados e discussões}

Em linhas gerais, o contexto do Pibid, enquanto espaço de atuação e formação, apresenta tanto obstáculos como avanços para o desenvolvimento de práticas de educação ambiental no contexto escolar. Foram identificados como obstáculos (a que se atribuiu o código 1) seis elementos, sendo eles: a) o comportamento normativo, b) a visão utilitarista da natureza, c) o foco na ação individual, d) o discurso da tecnologia enquanto solução para a crise socioambiental, e) ideia superficial da problemática ambiental, propagada geralmente por empresas através das grandes mídias e f) a inflexibilidade da grade escolar, sendo que, conforme indicado no quadro 1, os três primeiros obstáculos foram identificados como pertencentes ao mundo da vida, enquanto os demais foram vinculados ao sistema, relevandose as imbricações entre esses âmbitos, comentadas anteriormente.

No que se refere aos avanços, foram identificados oito elementos transformadores (código 2) para o desenvolvimento de práticas de educação ambiental, entre eles: a) a problematização no processo educativo, b) o entendimento do contexto histórico no qual estamos inseridas/os, c) o entendimento do processo de construção do conhecimento, d) o desenvolvimento de trabalhos a partir da dimensão dos valores (éticos e estéticos), e) a compreensão da realidade, f) o desenvolvimento de trabalhos a partir da dimensão da participação política, g) o procedimento do trabalho de campo e h) a diversidade presente tanto em relação à formação das/os bolsistas e das/os professoras/es que participaram do Pibid como em relação ao perfil das/os estudantes das escolas que participaram dos projetos. Todos esses elementos, conforme mostra o quadro 1, foram categorizados como pertencentes ao mundo da vida. Não foram identificados elementos transformadores pertencentes ao sistema.

Quadro 1- Elementos obstaculizadores e transformadores identificados nas práticas de educação ambiental na formação docente

\begin{tabular}{|c|c|c|}
\hline \multirow{3}{*}{ 焉 } & \multicolumn{2}{|c|}{ Tema e categorias } \\
\hline & \multicolumn{2}{|c|}{ Práticas de educação ambiental na formação docente } \\
\hline & Mundo da vida & Sistema \\
\hline 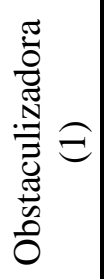 & $\begin{array}{c}\text { COMPORTAMENTO } \\
\text { NORMATIVO (1.a) } \\
\text { VISÃO UTILITARISTA DA } \\
\text { NATUREZA (1.b) } \\
\text { FOCO NA AÇÃO INDIVIDUAL } \\
(1 . c)\end{array}$ & $\begin{array}{l}\text { TECNOLOGIA (1.d) } \\
\text { MÍDIA (1.e) } \\
\text { GRADE ESCOLAR (1.f) }\end{array}$ \\
\hline 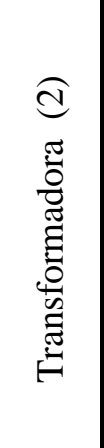 & $\begin{array}{c}\text { PROBLEMATIZAÇÃO (2.a) } \\
\text { CONTEXTO HISTÓRICO (2.b) } \\
\text { CONHECIMENTO (2.c) } \\
\text { VALORES (ÉTICOS E } \\
\text { ESTÉTICOS) }(2 . \mathrm{d}) \\
\text { COMPREENSÃO DA } \\
\text { REALIDADE (2.e) } \\
\text { PARTICIPAÇÃO POLÍTICA (2.f) } \\
\text { TRABALHO DE CAMPO (2.g) } \\
\text { DIVERSIDADE }(2 . \mathrm{h})\end{array}$ & \\
\hline
\end{tabular}

Fonte: TIBÚRCIO; LOGAREZZI, 2016. 
Conforme Tibúrcio e Logarezzi (2017), para Habermas o mundo da vida, previamente estabelecido por valores, códigos, ideias, um mundo por definição inquestionado, porém possivelmente questionável, é o contexto em que se desenvolvem as interações interpessoais, influenciando o agir comunicativo, às voltas com possíveis questionamentos que venham a tematizar aspectos cristalizados no mundo da vida, trazendo-os, no diálogo, para o plano do mundo objetivo, ou para o do mundo social ou para o do mundo subjetivo. Nesse sentido, o fato de as potencialidades advirem, exclusivamente, do âmbito do mundo da vida faz sentido, uma vez que nesse âmbito encontram-se maiores possibilidades (em relação ao sistema, marcado pelo engessamento institucionalizante de normas às voltas com o poder e com o dinheiro) para o estabelecimento do diálogo em busca de um entendimento que aponte para e subsidie ações coletivas em busca da superação das dificuldades encontradas. Uma espécie de consecução efetiva da agência humana na percepção dos problemas sociais e na busca da superação desses.

Um dos elementos identificados como obstáculo para a realização de uma educação ambiental dentro de uma perspectiva crítica foi a questão do comportamento normativo (1.a). De acordo com Carvalho, I. (2012, p. 180), um comportamento não necessariamente estará em consonância com uma atitude, uma vez que as atitudes estão ligadas a um sistema de valores "que será internalizado como uma visão de mundo orientadora dos posicionamentos do sujeito", enquanto os comportamentos são constituídos por "ações observáveis, efetivamente realizadas, e podem estar ou não de acordo com as atitudes do sujeito" (CARVALHO, I., 2012, p. 177).

\begin{abstract}
Por exemplo, na escola me incomoda muito essa história da reciclagem, porque você vê que fica esquecida a parte do reduzir, que eu acho muito mais importante. E na hora que você fala sobre diminuir o consumo às vezes el[a/]e [a/o estudante] nem percebeu esse processo (MONERA).
\end{abstract}

A discordância entre os comportamentos observáveis e as atitudes pode ser entendida como um dos maiores desafios da educação ambiental. Ainda nessa direção, Carvalho, I. (2012, p. 180) reflete sobre o fato de que ensinar o que fazer e o como fazer ambientalmente certo não garante a formação de uma atitude ecológica.

No Rio de Janeiro tem uma lei que se você jogar lixo na rua você toma multa. Aî fico pensando que às vezes essas ações não vão realmente mudar os valores dessa pessoa. Vai causar um impacto, ela vai se sentir mal porque vai perder dinheiro, mas será que isso vai ser realmente efetivo? Não sei... (PLANTAE).

Nesse sentido, gerar comportamentos individualizados não implica compreender os problemas ambientais e comprometer-se com a tomada de decisões, "entendendo o ambiente como uma rede de relações entre sociedade e natureza" (CARVALHO, I., 2012, p. 181). Além disso, "esse caráter normativo e disciplinar tende a produzir um efeito cerceador e restritivo [...] pouco estimulante para espaços de aprendizagem orientados pelos ideais de emancipação, liberdade e criatividade" (CARVALHO, I., 2012, p. 184).

Acho que o que a gente vive hoje [em 2015] aqui no estado de São Paulo, que é o problema da crise hídrica, ou supostamente uma crise hídrica, começa a colocar uma ideia na sociedade que é a de vigiar o outro. Parece que tem que vigiar, ficar vigiando se a pessoa gasta mais água ou gasta menos, ou se ela está tomando um banho mais longo ou não e aí depois do vigiar vem a punição. Essa é outra corrente que vem na sociedade fortemente: de punir sempre (PLANTAE). 
Tal discurso ignora a necessidade social das pessoas se reverem, refletirem e mudarem valores, habilidades e atitudes que reforçam a lógica do consumo e da desigualdade, se restringindo, somente, à dimensão do comportamento. Portanto, a educação ambiental crítica rompe com essa tendência reprodutivista das relações de poder, em que podemos nos afastar de um discurso vazio de salvação pela educação ou da normatização de comportamentos ecologicamente corretos, que, até hoje, prevalecem em algumas práticas de educação ambiental, geralmente, reproduzidas por empresas, grandes mídias e, muitas vezes, na própria escola, como, por exemplo, ensinar a realizar a separação dos tipos de resíduo, na chamada coleta seletiva de resíduo, mas não a entender a complexidade e a verdadeira origem dos problemas socioambientais associados a essa temática em particular e o seu papel no bojo da crise mais ampla.

A visão utilitarista da natureza (1.b) também foi identificada pelas pessoas participantes da pesquisa como obstáculo para se alcançar uma proposta crítica de educação ambiental. A visão antropocêntrica de superioridade dos seres humanos em relação aos demais foi considerada como aspecto negativo para um entendimento mais crítico e amplo da relação sociedade-natureza.

Você vai pensar que a questão de sustentabilidade é sempre: "porque futuramente as próximas gerações humanas não vão poder ter". Mas depois que eu entrei aqui no curso eu comecei a pensar: "e os outros seres vivos? E aquela barata?" Por mais que a gente não goste ou que tenha um olhar mais preconceituoso contra as baratas, ela também é um ser vivo! (PLANTAE).

Cavalari (2009) destaca que o conceito de natureza é algo construído historicamente, é produto da cultura, em que "cada sociedade, de acordo com sua cultura e com suas condições materiais de existência, constrói, elabora uma ideia de natureza" (p. 54) e que essa concepção será determinante nas relações estabelecidas entre essa sociedade e a natureza.

\begin{abstract}
Entender um pouco do processo, não a parte científica, mas o processo dessa educação ambiental, né? A integração da pessoa no ambiente, entender que ela incorpora o ambiente. A gente vê que muito sempre foi assim, o homem e a natureza, uma coisa separada, dicotômica, né? E pensar que ele faz parte de todo esse processo eu acho que é bem complicado. Então acho que é fundamental isso, esse conhecimento, essa integração [da mulher e] do homem ao ambiente. Se estiver falando de alun[a/]o, el[a/] entender que el[ [a/]e faz parte desse ambiente, né? Que el[a/]e não é uma coisa para cima, superior ao ambiente, como sempre foi falado. Então é a incorporação no processo. Fazer parte (MONERA).
\end{abstract}

Pensando que nossa sociedade moderna e ocidental tem como referência as tradições filosóficas e teológicas, que compreendem que "o mundo foi criado para o bem-estar e felicidade dos seres humanos e que as demais espécies devem apenas se subordinar a seus desejos e necessidades", a concepção construída sobre a natureza é de que ela "existe unicamente para servir aos interesses humanos" (CAVALARI, 2009, p. 54).

A gente vem há anos e anos de exploração. Sempre foi exploração. A gente vê poesias do século passado falando da utilidade dos animais (MONERA).

O foco na ação individual (1.c) também foi identificado pelas/os participantes como barreira para se alcançar uma educação ambiental crítica no contexto escolar.

Eu acho que a gente não buscava tanto colocar todas as ações sobre só o indivíduo, a gente tentava pensar nessa questão mesmo de como a sociedade como um todo vai proporcionando essas problemáticas. E aí interesses, valores estão fortes nisso. Porque se ficasse no indivíduo eu fico pensando sempre nessa questão da copa [do mundo]. O que um indivíduo só poderia fazer pra impedir aquela copa [de 2014]? 
Que ações no dia-a-dia dele mudariam ou impediriam que a copa acontecesse? É muito pobre para mim, é muito pouco. Ele parando de assistir futebol não ia impedir a copa de acontecer. (...) Ele indo sozinho lá na frente do palácio dos Bandeirantes não ia impedir da Dilma aceitar as obras. Então eu acho que trabalhar mais essa questão no coletivo é um dos caminhos que a gente tem que pensar educação ambiental (PLANTAE).

Carvalho, I. (2004, p. 19-20) reflete que o processo educativo não deve se limitar às intervenções centradas somente no indivíduo "tomado como unidade atomizada", o que retém a crença individualista de que a mudança social só ocorrerá na soma de atitudes comportamentais individuais "quando cada um[a/um] faz sua parte". As propostas educativas que priorizam e concebem essas perspectivas individuais podem ser enquadradas como sendo uma educação ambiental conservadora, pois assumem, por vários caminhos, a adaptação da/o educanda/o ao sistema social, afastando a possibilidade de transformação social (CARVALHO, I., 2004; GUIMARÃES, 2004; LOUREIRO, 2004).

Outro limite que se faz importante ressaltar aqui é o discurso da tecnologia (1.d) enquanto solução para a crise socioambiental.

\begin{abstract}
Como [a/]o professor[a/or] de ciências e tecnologia, de ciências convoca a questão da tecnologia na sociedade, qual o seu papel social, dos benefícios e malefícios da tecnologia? (...) Tecnologia não vai dar conta dos problemas que a gente tem hoje. Principalmente porque esses problemas são muito sociais. E para mim faz sentido quando eu penso na questão dos agrotóxicos, dos transgênicos. O discurso era "vamos acabar com a fome, então vamos usar agrotóxico que aumenta a produção”. Mas não acabou a fome. E parece que não vai acabar. E transgênicos a mesma coisa, né? É para aumentar a produção de alimentos, mas não resolve! É só o discurso mesmo e aí a tecnologia é usada de maneira cruel, às vezes perversa! Que acaba gerando um impacto que a princípio não era para ter, mas acaba tendo (PLANTAE).
\end{abstract}

Tendências conservadoras de educação ambiental, muitas vezes, ao adotarem uma perspectiva estritamente ecológica dos problemas ambientais esvaziada de dimensões políticas, sociais e culturais, reduzem a complexidade dessa problemática a uma questão de inovação tecnológica (LAYRARGUES; LIMA, 2011, p. 07), tratando a sustentabilidade como um mecanismo de mercado e ignorando aspectos ligados à mudança de paradigma das sociedades.

A ideia superficial da problemática ambiental propagada geralmente por empresas através das grandes mídias (1.e) também foi vista pelas pessoas do grupo de discussão comunicativo como uma barreira para se alcançar uma educação ambiental crítica. De acordo com Silva (2010, p. 278), os meios de comunicação de massa assumem papel fundamental na divulgação de informações acerca de assuntos da atualidade, incluindo a questão ambiental, influenciando na formação da opinião das pessoas que têm acesso a elas em diversos aspectos. Apesar do reconhecimento da importância do papel educativo que a mídia assume para tratar das questões ambientais, pode-se verificar certa fragilidade em relação às mensagens transmitidas, uma vez que as informações são, em geral, superficiais, priorizando a espetacularização e o catastrofismo (SILVA, 2010, p. 280).

Você vê empresas que falam que o produto é verde, né? É que agora virou moda produto verde para ganhar seu ISO não-sei-que-número e realmente a parte efetiva da sustentabilidade passa há anos luz. Porque você está estimulando o consumo. Por mais sustentabilidade que uma empresa tenha, ela tem extração, de recurso natural ou pessoal, das pessoas. Então eu tenho um pé atrás com essas propagandas de sustentabilidade, de empresa sustentável. Podemos até pensar que é um começo, um caminho, que pelo menos está começando, mas eu tenho medo. Eu sou meio desconfiada com essas coisas, com essa questão. Eu acho as vezes que é 
mais marketing do que realmente a preocupação. Eu fico muito preocupada com isso (MONERA).

Além disso, é comum o uso das grandes mídias para publicidade de produtos ditos sustentáveis, em que se estabelece um paradoxo da questão ambiental, estimulando o consumo, só que agora de produtos ecológicos (SILVA, 2010). Embora a questão da sustentabilidade seja assunto de grande importância, é preciso muita seriedade e responsabilidade na divulgação de informações relacionadas, levando em consideração aspectos não só ambientais, mas econômicos, políticos, sociais e culturais.

Para essas mesmas pessoas participantes, a inflexibilidade da grade escolar (1.f) dificulta o desenvolvimento da educação ambiental em uma perspectiva crítica ${ }^{7}$.

Uma escola que tem uma grade que não é tão rígida, a gente pode conversar e tal. Mas se for uma escola com uma grade muito rígida, fechadinha, aí pra introduzir a educação ambiental acho que bate nessa barreira da rigidez da grade, dos horários, dos compromissos (FUNGI).

Entendendo as/os educadoras/ores enquanto sujeitos políticos (FREIRE, 2005, p. 73) e que a escola enquanto espaço social também assume papel político, a organização dos conteúdos programáticos assim como a da grade curricular, da estrutura curricular, devem fazer parte das discussões ao longo da formação (tanto inicial quanto continuada) das/os docentes, das discussões do cotidiano da escola, uma vez que assume-se como necessário que a/o educadora/or tenha sempre em vista questionamentos como "que conteúdos ensinar, a quem, a favor de que, de quem, contra que, contra quem, como ensinar" (FREIRE, 2005, p. 45). Nesse sentido, verificamos, em outro recorte desta mesma pesquisa (TIBÚRCIO; LOGAREZZI, 2017), que a organização curricular está intimamente ligada a uma determinada ideia de educação, de conhecimento, de projeto de sociedade e, de acordo com Freire (2005, p. 72),

[...] nenhum[a/um] educador[a/or] faz a sua caminhada indiferente ou apesar das ideias pedagógicas de seu tempo ou de seu espaço. Pelo contrário, faz sua caminhada desafiad[a/]o por essas ideias que combate ou defende. Nega-se, afirmase, cresce, imobiliza-se, envelhece assim ou é sempre novo. Essas ideias, por outro lado, não são as fazedoras do mundo histórico e cultural, material, d[a/]o educador[a/or]. Elas expressam as lutas sociais, os avanços e os recuos que se dão na história mas, também, se fazem força atuante de mudança no mundo. Há uma relação dialética entre o mundo material que gera as ideias que podem interferir no mundo que as gera.

Por outro lado, no que diz respeito aos elementos identificados enquanto transformadores pelas/os participantes da pesquisa, a problematização (2.a) no processo educativo foi entendida pelo grupo como relevante para o desenvolvimento de práticas de educação ambiental em uma perspectiva crítica.

Para a pessoa poder criticar ela tem que ser questionada (ANIMALIA).

Carvalho, L. (2006, p. 38-39) pontua a importância dos temas controversos nas propostas de educação ambiental enquanto caminho para se questionar ideias aparentemente prontas em relação à temática ambiental, mas que podem (e devem) ser problematizadas.

Para chegar nesse momento de crítica acho que a gente tem que pensar nas contradições que tem em uma problemática, em uma situação. Por exemplo, para a questão da energia elétrica, dos carros elétricos. Da onde vem essa energia

7 Esse aspecto foi também identificado enquanto obstáculo em relação ao tema da interdisciplinaridade, apresentado em outro artigo (TIBÚRCIO; LOGAREZZI, 2017), no contexto desta mesma pesquisa. 
elétrica? Ah, vem das hidrelétricas. Mas as hidrelétricas têm um impacto ambiental grande. Então apesar de ter um discurso de que o carro elétrico é menos poluente, ou que é mais ecológico, a própria geração de energia está sendo impactante. Então acho que essas contradições que mobilizam um pouco esse espírito crítico (PLANTAE).

Para tanto, Bonotto (2008) cita o diálogo como um valor importantíssimo a ser desenvolvido com as/os educandas/os, o qual pode ser trabalhado a partir de uma situação controversa e concreta, como também, na apreciação estética de uma obra artística ou na expressão artística própria da/o educanda/o. Nesse sentido, na educação, que por ser um ato político não pode ser neutra, ser educadora/or crítica/o, democrática/o e progressista é agir no e com o contexto socio-histórico, é obrigatoriamente assumir a politicidade da sua prática. Portanto, um ato constante na/o educadora/or progressista deve ser o de problematizar e é através de uma educação problematizadora que se caminha na direção da transformação social.

O entendimento do contexto histórico no qual estamos inseridas/os (2.b) também foi identificado como potente para a transformação de práticas relativas ao tema aqui em foco.

Acho que [para que a educação ambiental seja crítica é fundamental] compreender os principais momentos históricos de cada sociedade. Aqui no Brasil ficou bem forte o momento de escravidão, depois o momento de monarquia. E acho que isso influencia bastante a maneira como a gente usa os recursos e também como estão distribuídas as diversas classes, digamos assim. Então, por exemplo, existe uma classe que é muito pobre economicamente e essa classe também utiliza desses recursos naturais, só que quem ganha, quem lucra com os recursos são as camadas mais ricas. Então é meio que desigual. Eu acho desigual essa distribuição de riqueza. Eu acho que isso tem a ver com o processo histórico do Brasil (PLANTAE).

Freire (2001, p. 35) reflete sobre a história enquanto "tempo de possibilidade e não de determinações", e isso implica pensarmos a educação como um espaço em busca da compreensão crítica da história, em busca de alternativas que caminhem na direção da libertação daquela condição, entendendo-nos enquanto sujeitos atuantes.

$\mathrm{O}$ entendimento do processo de construção do conhecimento (2.c) nas suas diferentes naturezas e contextos também foi destacado como elemento transformador pelas/os participantes da pesquisa.

Pensar não só o conhecimento que a gente constrói aqui na universidade, mas também o conhecimento que é chamado popular, o conhecimento que veio ao longo de gerações tendo uma sistematização específica. Acho que essa relação entre os dois conhecimentos possibilita um espírito crítico (PLANTAE).

De acordo com o que pudemos verificar na análise de outro tema da pesquisa (TIBÚRCIO; LOGAREZZI, 2017), o entendimento sobre como se dá a construção do conhecimento possibilita a construção de uma nova racionalidade e, nesse sentido, a compreensão desse processo pode contribuir para uma perspectiva crítica de educação ambiental. Sendo assim, é fundamental que os conhecimentos oriundos de diferentes contextos sejam igualmente considerados. Dessa forma, entendemos que o diálogo entre o saber científico, conhecimento produzido na universidade, e o saber popular, conhecimento construído a partir da experiência contextual, particularmente na escolar, pode proporcionar uma maior criticidade. Freire (2005) fala da importância do saber de experiência feito que as/os educandas/os trazem para a escola e que, nesse sentido, as/os educadoras/es não devem minimizar, desprezar esses saberes, respeitando as vivências das/os educandas/os de outros contextos, entendendo que o conhecimento precisa ser reconhecido como uma produção social, que resulta da ação e da reflexão imbricadas dialeticamente na práxis e, também, da curiosidade em constante movimento de procura. Além disso, entendendo que esse diálogo constitui uma interação 
social, é necessário que haja mais de uma subjetividade, outros seres humanos, além de uma linguagem comum, para que esses sujeitos possam dizer o mundo uns aos outros, transformando pensamento em matéria para, assim, (re)fazer e transformar a realidade. Ou seja, é preciso uma relação intersubjetiva (sujeito-sujeito) a partir de um processo coletivo dialético e dialógico sobre o mundo (sujeito-objeto-sujeito).

As pessoas participantes da pesquisa também reconheceram como de fundamental importância o desenvolvimento de trabalhos a partir da dimensão dos valores (éticos $e$ estéticos) (2.d) para se alcançar uma educação ambiental crítica.

\begin{abstract}
$O$ conhecimento não é suficiente, a gente tem que pensar também nos valores. $E$ valor é uma coisa complicadíssima de trabalhar, né? Porque além da formação cultural da sociedade, das sociedades, tem também a parte dos outros vieses políticos, ideológicos. E isso tudo vai influenciando. [...] Mas acho muito interessante pensar o estético como faculdade do sentir, você ir para o ambiente e sentir aquele ambiente, desde os sons, cheiros, olhares, visões. Um[a/um] alun[a/]o chegando ao ambiente pode ter diferentes olhares, né? Não só o olhar que el[a/]e tem da história de vida del[a/]e, mas de outros grupos. Então como um[a/um] empresári[a/]o olharia aquele ambiente? Como um[a/um] trabalhador[a/or], operári[a/]o, olharia aquele ambiente? Como supostamente [uma mulher ou] um homem da caverna olharia aquele ambiente? Acho que muda muito essas visões e isso também possibilita essa alteridade de sentimentos, de conhecimentos" (PLANTAE).
\end{abstract}

Dessa forma, uma educação ambiental crítica precisa considerar aspectos axiológicos do conhecimento, propondo situações em que as/os educandas/os sejam levadas/os a fazer juízos de valores éticos e estéticos. Assim, de acordo com Bonotto (2012, p. 36), a partir de uma proposta de trabalho com valores em educação ambiental é possível proporcionar uma formação apropriada, "voltada para a construção da cidadania e de um mundo mais justo e equilibrado em termos sociais e ambientais", que nos guie na direção de uma nova relação com o ambiente, tanto o natural como o construído, valorizando nosso papel de ser ao mesmo tempo natural e social, na perspectiva de natureza como totalidade do real, tal como descrita por Loureiro (2014, p. 58-59).

Além disso, a compreensão da realidade (2.e) a que pertencemos foi identificada pelas/os participantes da pesquisa enquanto elemento fundamental para se caminhar na direção do desenvolvimento de uma educação ambiental crítica.

\begin{abstract}
Eu acho que essa compreensão da educação ambiental crítica vem no sentido de entender a realidade e transformá-la. De maneira bem sucinta, bem sintética seria compreender esse ambiente que a gente vive e transformá-lo, no sentido de buscar uma democracia, buscar uma sociedade mais justa. É um dos princípios que regem a democracia (PLANTAE).
\end{abstract}

Para Freire (2011) o conhecimento e a transformação da realidade estão dialeticamente conectados, porém, o desvelamento da realidade não significa, necessariamente, sua transformação. O reconhecimento das contradições presentes na realidade, chamadas por Freire (2013) de percebidos destacados, é a primeira etapa do processo de busca do ser mais. Mas, para se alcançar isso são necessários atos limites, consciente e politicamente definidos, que caminhem na direção dos inéditos viáveis. Sendo assim, podemos dizer que no processo de conscientização é possível se alcançar uma compreensão mais profunda da realidade e, dessa forma, de como atuar para transformá-la, destacando-se que esse aprofundamento da compreensão e essa atuação para transformação se dão imbricada e simultaneamente. 
A participação política (2.f), no sentido da denúncia das contradições e do anúncio de uma nova possibilidade de realidade, foi considerada como elemento transformador para uma educação ambiental crítica de acordo com o grupo participante da pesquisa.

\begin{abstract}
O ser crítico que eu penso é o ser que traz solução, ou busca solução. A crítica por si só não leva a nada, né? Eu acho que se você conseguir um[a/um] alun[a/]o que é crític[a/]o àquela situação, que para pra refletir sobre uma solução, é ai que eu acho que a gente tem que chegar. Não só o levantamento da problemática, mas também uma solução para aquela problemática. Fazer a pessoa ficar resignada e parar um pouquinho para pensar: "o que eu posso tentar para ajudar nesse esquema?”; "o que eu posso estar mudando?” (...) Eu acho que ser crítico é você levantar o problema e achar soluções, porque só falar que está errado e não tentar nem pensar no que pode melhorar, isso não serve para nada. Acho que crítico para mim é isso, que fala do problema e tenta, pelo menos, achar solução. Eu acho que crítico é isso. Um crítico efetivo (MONERA).
\end{abstract}

Para Freire (2001), a construção politizada do conhecimento se dá a partir da reflexão crítica da realidade em que estamos inseridas/os, a partir "da busca de uma educação denunciante da opressão e anunciante da liberdade" (FREIRE, 2005, p. 73). Nesse sentido, Carvalho, L. (2006, p. 27) aponta como fundamental que a dimensão da participação política esteja presente no desenvolvimento de práticas de educação ambiental para que ela assuma uma perspectiva crítica, tendo como meta "a formação de [cidadãs e] cidadãos e a construção de uma sociedade democrática".

A parte de ação política vem no sentido de mobilização mesmo, de como atuar frente a essas problemáticas (PLANTAE).

Assim, entendendo a educação enquanto um ato político, um ato de escolha, de decisão, Freire (2001) mostra a inseparabilidade do político com o educativo e demonstra sua preocupação na necessidade da formação política da/o educadora/or, assim como da/o educanda/o. Nesse sentido, pudemos observar a partir de relatos do próprio grupo de bolsistas Pibid que, a partir de momentos coletivos de reflexão, ao perceberem certa distância entre seus discursos (sobre a importância da participação política na educação) e suas posturas (não envolvimento em âmbitos políticos dentro da universidade), algumas/ns bolsistas começaram a participar de espaços de discussão relacionados ao curso de ciências biológicas, além de participarem enquanto representantes de espaços como o centro acadêmico e órgãos colegiados (conselho de curso, conselho permanente de ensino, conselho de departamentos etc.).

O procedimento de trabalho de campo (2.g) utilizado pelo grupo para o desenvolvimento de práticas de educação ambiental foi considerado transformador.

\begin{abstract}
Eu acho que essa proposta de trabalho de campo ela é muito rica. Eu vejo muito pouco, no nosso curso mesmo, a gente tem campos pontuais, em uma disciplina ou em outra. E na verdade quando a gente sai da sala de aula, sai aqui da faculdade, da universidade a gente vê realmente os ambientes, os diferentes ambientes, construídos e transformados - ou não - e isso possibilita outra compreensão. $\dot{E}$ diferente a gente ver por slide as diferentes formações de cerrado (campo limpo, sujo, stricto sensu, latu senso, cerradão) e quando a gente vai aqui para Itirapina ou vai lá para Porto Ferreira... Nesse caminho dá para a gente ver as diferentes formações. E aí que a gente sente mesmo como as diferentes questões do ambiente regulam, modulam essa distribuição das plantas (PLANTAE).
\end{abstract}

O trabalho de campo, ao mesmo tempo em que é complexo, possibilita o desenvolvimento de práticas de educação ambiental a partir da problematização e investigação da realidade em questão. Para que o trabalho de campo se consolide de forma crítica é preciso que todas as 
pessoas participantes da atividade se disponham a um envolvimento real com o trabalho como um todo e que a/o educadora/or tenha preocupação com as etapas anteriores ao campo em si, como um plano de desenvolvimento da atividade que não se limite a aspectos de ordem prática, como propõe Carvalho, L. (1999, p. 38), assim como uma visita prévia ao local.

\footnotetext{
Eu gosto muito de valorizar o jardim da escola, acho que é um ambiente extremamente rico, onde a gente vê evidências, vê um monte de coisas que a gente pode trabalhar dentro da sala de aula, e pode trabalhar dentro da perspectiva da educação ambiental (PLANTAE).
}

Apesar de esse procedimento didático ser de grande valor pedagógico, por possibilitar o desenvolvimento de atividades tanto em ambientes naturais como em ambientes alterados por nós, seres humanos, cabe lembrar a "inexistência de fórmulas prontas ou de conjuntos definidos de modalidades didáticas como se fossem próprias da educação ambiental" (CARVALHO, L., 1999, p. 39), havendo necessidade de que o trabalho de campo tenha como perspectiva o ensino, com finalidade definida e com um planejamento que contemple os aspectos anteriormente comentados. As discussões indicaram que esses aspectos são relevantes e que o Pibid é um espaço oportuno para serem considerados.

Finalizando os elementos identificados em relação ao tema da educação ambiental, as/os participantes reconheceram que a diversidade (2.h), presente tanto em relação à formação das/os bolsistas e das/os professoras/es que participaram do Pibid como em relação ao perfil das/os estudantes das escolas que participaram dos projetos, também foi um elemento transformador para o trabalho.

\begin{abstract}
Eu achei bem rico a oficina [interdisciplinar desenvolvida com estudantes da escola no ano de 2012, ao longo do projeto "Corra para salvar a floresta"] porque a gente possibilitava ter um[a/um] alun[a/]o de quinta série com um de oitava série, um[a/um] do sexto ano com um[a/um] de nono ano. Possibilitava alun[as/]os de diferentes idades interagindo entre si, né? Aquele negócio da amizade de diferentes idades possibilitando a construção do conhecimento (PLANTAE).
\end{abstract}

Para Freire (2011), a unidade na diversidade - a união entre diferentes pessoas que estão dispostas a dialogar e avançar em busca do ser mais, sem que uma se sobreponha a outra na interação - pode ser o caminho para a transformação da realidade. Além disso, de acordo com o que pudemos verificar na análise de outro tema da pesquisa (TIBÚRCIO; LOGAREZZI, 2017), a diversidade também possibilita o diálogo de saberes, entre pessoas de diferentes contextos, favorecendo a interdisciplinaridade no contexto escolar.

\title{
4 Considerações
}

A partir dos dados empíricos obtidos com base em uma perspectiva coletiva, de todas/os as/os participantes da pesquisa, tendo em vista tanto os elementos transformadores quanto os obstaculizadores para o desenvolvimento de práticas de educação ambiental em uma abordagem crítica por professoras/es em formação inicial e continuada no contexto escolar, apresentamos algumas considerações no sentido de contribuir com a discussão teórica sobre o tema e de apontar para ações de superação das dificuldades verificadas com o aproveitamento das fortalezas também verificadas, visando a transformação da realidade pelas pessoas envolvidas no processo de pesquisa.

Dos limites identificados pelo grupo participante da pesquisa, três foram considerados pertencentes ao mundo da vida, enquanto outros três foram associados ao âmbito do sistema, como mostra a primeira linha do quadro 1. Todos os elementos associados ao primeiro âmbito 
são aspectos ligados a práticas educativas de caráter conservador, que podem ser superados pela/o educadora/or a partir de suas escolhas em relação à preparação e à condução das aulas.

As/os bolsistas participantes do subprojeto em questão, por participarem de um grupo Pibid coordenado por professoras/es pesquisadoras/es da linha de pesquisa em educação ambiental da Unesp, tiveram a oportunidade de se aprofundar nos estudos e nas discussões sobre a questão ambiental e a educação, o que favoreceu uma formação mais qualificada enquanto educadoras/es ambientais. Nesse mesmo sentido, a possibilidade de aprofundar a discussão sobre os aspectos tratados, incluindo o tema da educação ambiental, ao longo da pesquisa, foi considerada como uma experiência rica pelas pessoas participantes, como podemos verificar na seção III da dissertação que este artigo compõe (TIBÚRCIO, 2016, p. 126-133).

Algumas outras potencialidades vivenciadas pelas/os bolsistas, que não foram registradas nos grupos de discussão comunicativos, mas estiveram presentes no desenvolvimento do trabalho - e que estão diretamente ligadas ao contexto particular do Pibid - se referem ao fato do grupo ter a dedicação de mais de trinta horas mensais para o projeto, às reuniões coletivas e interdisciplinares para se pensarem as atividades e ao acesso aos recursos financeiros proporcionados pela Capes para o desenvolvimento de práticas diferenciadas de ensino. Em relação ao procedimento de trabalho de campo utilizado pelo grupo, além desses fatores que facilitaram, de certa forma, a sua execução, podemos considerar também como elemento facilitador o número de pessoas diretamente envolvidas em sua organização (no caso, dezesseis bolsistas, além da professora supervisora).

Quando pensamos nas atuais condições de trabalho docente e de organização escolar da rede pública de ensino podemos notar que as possibilidades para o desenvolvimento de trabalhos educativos dessa natureza se tornam mais restritas. Dentre os inúmeros fatores que limitam essa atuação, chamamos a atenção, em especial, para a formação docente e seu currículo com pouco ou nenhum conteúdo de educação ambiental, ficando mais restrita aos cursos de licenciatura em ciências biológicas. Isso faz com que um tema transversal como a questão ambiental seja entendido como atribuição da/o professora/or de ciências e/ou biologia, fazendo com que se percam ou se limitem as possibilidades de um trabalho interdisciplinar nessa direção.

Nesse sentido, o subprojeto do Pibid em questão ofereceu, em especial às/aos estudantes do curso de educação física, a possibilidade de um contato mais aprofundado com a temática, contribuindo, assim, para sua atuação enquanto educadoras/es ambientais. Outros desafios enfrentados pelo grupo não foram registrados nos grupos de discussão comunicativos, mas estiveram presentes no desenvolvimento do trabalho, entre eles o elevado número de estudantes nas salas de aula (entre 35 e 40).

Em relação às possibilidades identificadas pelas/os participantes da pesquisa ao longo do processo, todas foram classificadas como pertencentes ao mundo da vida, não havendo nenhum elemento transformador considerado como pertencente ao âmbito do sistema, como aparece na segunda linha do quadro 1. Além disso, em um panorama geral, os elementos considerados transformadores são um pouco mais numerosos (oito) quando comparados aos elementos obstaculizadores (seis).

Entre esse conjunto de elementos considerados transformadores, estiveram presentes os elementos que compõem as três dimensões da práxis humana a serem consideradas como possíveis orientações para o desenvolvimento de ações educativas em uma perspectiva crítica - conhecimento, valores éticos e estéticos e a participação política -, de acordo com Carvalho, L. (2006).

Cabe ressaltar a importância que programas como o Pibid ganham enquanto espaço de formação que oferece um contato mais estreito entre as/os estudantes de licenciatura e o 
contexto escolar, a partir de um trabalho coletivo e, no caso em questão, interdisciplinar. Dessa forma, imersas/os na realidade da escola as/os licenciandas/os se deparam com as limitações ali existentes e, coletivamente, pensam em caminhos para a superação desses desafios. Além disso, de acordo com outro recorte desta mesma pesquisa (TIBÚRCIO; LOGAREZZI, 2016, p. 120), o Pibid possibilitou ao grupo participante da pesquisa a construção, a organização, o planejamento e o desenvolvimento das atividades em um arranjo peculiar, de forma solidária e coletiva, arranjo pouco presente tanto nos cursos de formação inicial quanto na escola. Além disso, o envolvimento das/os estudantes de graduação em espaços políticos da universidade como reflexo de suas discussões coletivas a partir do espaço do Pibid evidencia a importância de programas como esse para a formação de professoras/es reflexivas/os, conscientes de sua realidade e engajadas/os na luta pela melhoria da educação pública.

Com Carvalho, M. (2012, p. 25), para quem,

\begin{abstract}
[...] em qualquer âmbito ou instância de pensamento e ação, a sociedade conta com [as educadoras e] os educadores ambientais para dar outro rumo à nossa relação com a Terra, abrindo as mentes, eliminando o falso e prevalente conceito utilitarista, tentando suplantar os interesses do sistema hegemônico, para o qual a ética humana universal (FREIRE, $1996^{8}$ ) responsável por equilibrar nossas relações com o meio em que vivemos, quer seja natural ou social, é desconsiderada, dando lugar à satisfação de necessidades que nem sempre são vitais,
\end{abstract}

apresentamos, como reflexão última deste artigo, a importância de trabalhos com educação ambiental em contextos formais de educação, tanto na educação da rede básica quanto nas instituições de ensino superior e, dessa forma, ressaltamos a importância da luta por políticas públicas que valorizem a carreira docente em geral, em particular no que tange à formação de educadoras/es ambientais. Entendemos que não há uma única forma de se desenvolver trabalhos de educação ambiental, mas consideramos trabalhos desenvolvidos a partir de uma abordagem crítica pautada em relações dialógicas como escolhas potentes para se promover a transformação da realidade em que vivemos, a partir do papel social do campo da educação, desempenhado em especial no contexto da escola.

\title{
Referências
}

BONOTTO, D. M. B. Contribuições para o trabalho com valores em educação ambiental. Ciência e Educação, Bauru, v. 14, n. 2, p. 295-306, 2008.

BONOTTO, D. M. B. Educação ambiental e o trabalho com valores. In: ; CARVALHO, M. B. S. S. (Orgs.). Educação ambiental e o trabalho com valores: reflexões, prática e formação docente. São Carlos: Pedro \& João Editores, 2012, p. 35-55.

CARVALHO, I. C. M. Educação ambiental crítica: nomes e endereçamentos da educação. In: LAYRARGUES, P. P. (Coord.) Identidades da educação ambiental brasileira. Brasília: Ministério do Meio Ambiente, 2004, p. 13-24.

CARVALHO, I. C. M. Educação ambiental: a formação do sujeito ecológico. 6 ed. São Paulo: Cortez, 2012.

CARVALHO, L. M. Educação e meio ambiente na escola fundamental: perspectivas e possibilidades. In: Projeto - Revista em educação: Ciências: que tema eleger? Porto Alegre, v. 1, n. 1, p. 35-39, 1999.

\footnotetext{
${ }^{8}$ FREIRE, P. Pedagogia da autonomia: saberes necessários à prática educativa. São Paulo: Paz e Terra, 1996.
} 
CARVALHO, L. M. A temática ambiental e o processo educativo: dimensões e abordagens. In: CINQUETTI, H. C. S.; LOGAREZZI, A. J. M. (Orgs.). Consumo e resíduo: fundamentos para o trabalho educativo. São Carlos: Edufscar, 2006, p. 19-41.

CARVALHO, M. B. S. S. Universidade e escola: construindo espaços de formação. In: BONOTTO, D. M. B.; CARVALHO, M. B. S. S. (Orgs.). Educação ambiental e o trabalho com valores: reflexões, prática e formação docente. São Carlos: Pedro \& João Editores, 2012, p. 19-33.

CAVALARI, R. M. F. Las concepciones sobre la naturaleza en el ideario educacional de Brasil durante las décadas de 1920 y 1930. Utopía y Praxis Latinoamericana, Maracaibo, v. 44, p. 53-67, 2009.

FIORI, E. M. Aprender a dizer a sua palavra. In: FREIRE, P. Pedagogia do oprimido. 55 ed. Rio de Janeiro: Paz e Terra, 2013, p. 11-30.

FLECHA, R. Compartiendo palabras: el aprendizaje de las personas adultas a través del diálogo. 7 ed. Barcelona: Paidós, 2014.

FREIRE, P. Política e educação. 5 ed. São Paulo: Cortez, 2001.

FREIRE, P. A educação na cidade. 6 ed. São Paulo: Cortez, 2005.

FREIRE, P. Pedagogia da esperança: um reencontro com a Pedagogia do oprimido. 9 ed. São Paulo: Paz e Terra, 2011.

FREIRE, P. Pedagogia do oprimido. 55 ed. Rio de Janeiro: Paz e Terra, 2013.

GÓMEZ, J.; LATORRE, A.; SANCHEZ, M.; FLECHA, R. Metodología comunicativa crítica. Barcelona: El Roure Editorial, 2006.

GRUN, M. Ética e educação ambiental: a conexão necessária. Campinas: Papirus, 2001.

GUIMARÃES, M. Educação ambiental crítica. In: LAYRARGUES, P. P. (Coord.) Identidades da educação ambiental brasileira. Brasília: Ministério do Meio Ambiente, 2004, p. 25-34.

HABERMAS, J. Teoria do agir comunicativo, 1: racionalidade da ação e racionalização social. São Paulo: Ed. WMF Martins Fontes, 2012a.

HABERMAS, J. Teoria do agir comunicativo, 2: sobre a crítica da razão funcionalista. São Paulo: Ed. WMF Martins Fontes, 2012b.

LAYRARGUES, P. P.; LIMA, G. F. C. Mapeando as macrotendências político-pedagógicas da educação ambiental contemporânea no Brasil. In: VI Encontro Pesquisa em Educação Ambiental, 2011, Ribeirão Preto. VI Encontro Pesquisa em Educação Ambiental: a pesquisa em educação ambiental e a pós-graduação. Ribeirão Preto: USP, 2011. P. 01-15.

LEFF, E. Epistemologia ambiental. São Paulo: Cortez, 2002.

LOGAREZZI, A. J. M. Educação ambiental em resíduo: uma proposta de terminologia. In: CINQUETTI, H. C. S.; LOGAREZZI, A. J. M. (Orgs.). Consumo e resíduo: fundamentos para o trabalho educativo. São Carlos: Edufscar, 2006, p. 85-117. 
LOUREIRO, C. F. B. Educação ambiental transformadora. In: LAYRARGUES, P. P. (Coord.) Identidades da educação ambiental brasileira. Brasília: Ministério do Meio Ambiente, 2004, p. 65-84. 109.

LOUREIRO, C. F. B. Educação ambiental crítica: contribuições e desafios. In: MELLO, S.; TRAJBER, R. (Orgs.) Vamos cuidar do Brasil: conceitos e práticas em educação ambiental. Brasília: MEC/Unesco, 2007, vol. 1, p. 65-73.

LOUREIRO, C. F. B. Materialismo histórico-dialético e a pesquisa em educação ambiental. Pesquisa em Educação Ambiental, Rio Claro, v. 9, n. 1, p. 53-68, Jun. 2014. Disponível em: <http://www.periodicos.rc.biblioteca.unesp.br/index.php/pesquisa/index >. Acesso em: 26 out. 2014.

LOUREIRO, C. F. B.; TREIN, E.; TOZONI-REIS, M. F. C.; NOVICKI, V. Contribuições da teoria marxista para a educação ambiental crítica. Caderno Cedes, Campinas, v. 29, n. 77, p. 81-97, jan./abr. 2009.

SATO, M. Debatendo os desafios da educação ambiental. In: Congresso de Educação Ambiental Pró Mar de Dentro, 1, 2001, Rio Grande. Anais... Rio Grande: Mestrado em Educação Ambiental, FURG \& Pró Mar de Dentro, 2001, p. R14-R35.

SAUVÉ, L. Uma cartografia das correntes em educação ambiental. In: SATO, M.; CARVALHO, I. C. M. (Orgs.) Educação ambiental: pesquisa e desafios. Porto Alegre: Artmed, 2005, p. 17-44.

SILVA, R. L. F. Leitura de imagens da mídia e educação ambiental: contribuições para a formação de professores. Educação em Revista, Belo Horizonte, v. 26, n. 2, p. 277-298, ago. 2010.

TIBÚRCIO, G. S. Desafios e possibilidades do Pibid: uma análise das práticas docentes em educação ambiental de educadoras/es em formação inicial dos cursos de biologia e de educação física da Unesp de Rio Claro. 2016. 161 f. Dissertação (Mestrado em Ciências Ambientais) - Centro de Ciências Biológicas e Saúde, Universidade Federal de São Carlos, São Carlos, 2016.

TIBÚRCIO, G. S.; LOGAREZZI, A. J. M. O Pibid como possibilidade de integração entre as formações inicial e continuada de professoras/es. In: TIBÚRCIO, G. S. Desafios e possibilidades do Pibid: uma análise das práticas docentes em educação ambiental de educadoras/es em formação inicial dos cursos de biologia e de educação física da Unesp de Rio Claro. 2016. 161 f. Dissertação (Mestrado em Ciências Ambientais) - Centro de Ciências Biológicas e Saúde, Universidade Federal de São Carlos, 2016.

TIBÚRCIO, G. S.; LOGAREZZI, A. J. M. Interdisciplinaridade e educação ambiental no Pibid: diálogos entre sujeitos no contexto de múltiplas disciplinas e múltiplos saberes. Revista Eletrônica do Mestrado em Educação Ambiental, Rio Grande, v. 34, n. 2, p. 318-339, mai./ago. 2017. 